\title{
ENERGY USE OPTIMIZATION IN VENTILATION OF OPERATING ROOMSDURING INACTIVITY PERIODS
}

Tejero González, Ana; De Freitas Barros Galvão, Víctor M.; Zarzuelo Sánchez, Andrés M.; San José Alonso, Julio F.

This is an Accepted Manuscript of an article published by Routledge (Taylor \& Francis Group):

Building Research and Information, vol. 49 2021, issue 3, Pages 308-324 https://doi.org/10.1080/09613218.2020.1817723

$$
\text { (c) }(\overline{\mathrm{B}} \Theta
$$




\begin{abstract}
Hospitals are highly energy demanding buildings, where simple actuations can involve large savings. However, energy efficiency actions must comply with the high safety standards. Operating rooms demand continuous ventilation despite the short activity periods. Setback during non-occupation of the operating rooms can reduce ventilation loads but must not hinder indoor overpressure to avoid infiltrations. Besides, it prevents any existing heat recovery system from operation. This work evaluates setback ventilation in operating rooms at a case study in Spain, from two approaches: its effect on indoor overpressure and its preference to an existing coil heat recovery (runaround) loop. It bases on monitored data of two operating rooms under setback and normal ventilation with operation of the heat recovery system. Seven tests are performed throughout the year, whose comparison to estimated results enables extrapolation to yearly operation. Results show that indoor overpressure maintain at $15 \mathrm{~Pa}$ under setback, thus meeting current and coming standards. Setback turned to be always preferable to hear recovery under cooling needs. Estimated heating and electric yearly supply energy savings reach $29 \mathrm{MWht}$ and $262 \mathrm{MWhe}$, the latter accounting for $2 \%$ of the total electric energy consumption of the hospital during 2019.
\end{abstract}

\title{
Keywords
}

Hospital, operating room, ventilation setback, heat recovery, indoor overpressure, energy savings 


\section{Introduction}

The concerns on energy use in buildings yields further attention on strategies such as the reduction of the energy demand, the use of renewable energy sources, improvement of Heating, Ventilation and Air Conditioning (HVAC) systems efficiency and heat recovery of residual energy (The European Parliament and the Council of the European Union, 2018). However, their implementation in hospitals can be delicate.

Hospitals are a particular case because safety always comes before efficiency, despite their potential for energy savings due to being high energy demanding buildings (ASHRAE, 2019; Joppolo \& Romano, 2017; Sala, Alcamo, \& Ceccherini Nelli, 2017). Their average energy consumption per square meter is 2.7 times that of a commercial building (Pastor Pérez, 2012). This is due to: a) a continuous, uninterrupted yearly use; b) high ventilation rates for the exigent Indoor Air Quality (IAQ) requirements; c) strict thermal comfort requirements, often beyond common conditions due to medical needs, requiring flexible and high-power systems; and, finally, d) the energy consumption of medical equipment, which also generates heat to be dissipated by the HVAC systems.

In Spain, there exist near 800 hospitals, most of them public: 108,000 of a total of about 160,000 beds are in public hospitals (Ramos, 2018). Energy consumption in Spanish hospitals reached $847 \mathrm{ktoe}$ in 2017 , corresponding to $8.5 \%$ of the energy consumed in the service sector (IDAE, $2001)$. The consequent ratio of energy consumption per bed in Spain is in the range from 20 to $60 \mathrm{MWh} /$ bed yearly, with an average value of $28 \mathrm{MWh} /$ bed per year (Pastor Pérez, 2012). These figures correspond to the expected ones in developed countries. According to the Centre for the Analysis and Dissemination of Demonstrated Energy (CADDET) (CADDET, 1997), average yearly figures for the thermal energy consumed are above $5 \mathrm{MWh} / \mathrm{bed}$ for Italy, about 10 $\mathrm{MWh} / \mathrm{bed}$ for Belgium and The Netherlands, $20 \mathrm{MWh} / \mathrm{bed}$ in Sweden and about 23 and 28 $\mathrm{MWh} /$ bed in Canada and Austria, respectively.

The need for energy savings in hospitals also reflect in the economic costs related. In Spain, the energy consumption in the public sector goes up to 70 billion euros, representing $6.5 \%$ of the Spanish Gross Domestic Product (Sánchez-Barroso Moreno, García-Sanz Calcedo, González, \& Salgado, 2019). In Germany, where the energy consumption nearly reached 1.5 Mtoe in 2015 , 2100 hospitals consume 1.5 billion of euros only in energy, which represents $2.5 \%$ of health general expenses (González González, García-Sanz-Calcedo, \& Rodríguez Salgado, 2018).

HVAC systems play a non-negligible role amid the final energy use. As happens in cleanrooms, the high ventilation requirements make these spaces energy intensive (Loomans, Molenaar, Kort, \& Joosten, 2019). In Spain, they are responsible for $45 \%$ of this consumption, followed closely by lightning (35\%) (FENERCOM, 2012). In the United States, the National Grid energy company (NationalGrid, 2002) analysed the energy consumption in the US hospitals in terms of the degree-days of five climatic zones. Energy consumed for HVAC systems ranged from $21 \%$ to $46 \%$ of the final energy consumption depending on the climate. They propose several recommendations towards a more efficient energy use, among which they propose HVAC setback to reduce airflows while maintaining air-pressure needs. 


\subsection{Energy efficiency actions in hospitals and operating rooms}

Aiming for a more energy efficient use in hospitals, institutions and agencies of different countries have developed best practice guides (EPTA, 2007; USAID/GOI, 2009); the same happens in Spain (FENERCOM, 2012; IDAE, 2001).

Many studies focus on how to improve the energy efficiency in hospitals. Sala et al. (Sala et al., 2017) proposed a wide range of bioclimatic approaches, energy generation to improve energy use in five European hospitals in different climates. Concerning ventilation, they promoted ventilative cooling when possible. Short et al. (Short \& Al-Maiyah, 2009) scoped the potential of low energy ventilation and ventilative cooling, estimating up to $70 \%$ of hospitals area's surface to possibly be naturally conditioned, at least partly. Yau\&Ng. (Yau \& Ng, 2011) discussed transitory simulations to test the heat recovery equipment energy efficiency in warm and humid areas, concluding that heat-pipe avoided proliferation of fungi and involved the largest efficiency $(57.85 \%)$, being the payback period lower than one year. Garcia-SanzCalcedo et al. (García-Sanz-Calcedo, Al-Kassir, \& Yusaf, 2018) proposed multiple action lines on HVAC systems, expecting a decrease in the energy consumption of large hospitals of up to $1.8 \mathrm{kWh} / \mathrm{m}^{2}$, with a payback period shorter than 2.5 years. Dyer\&O'Mary (Dyer \& O'Mary, 2011) estimated 5,000 $\$$ /year savings through indoor conditions control during non-occupation at the Russel Medical Center, in Alabama (USA).

Operating rooms are areas of particular risk. Their HVAC systems must ensure four targets: a) achieve particular indoor comfort; b) avoid air infiltrations from outside the operating room; c) control the indoor concentration of particles, Colony Forming Units, organic volatile compounds, etc. generated by the indoor activity and from the outside; and d) create an airflow pattern that prevents polluted air to reach the operating table or the instruments and that takes away particles and droplets from the operating table, generated during the activities from the patient and the surgery team.

Consequently, when applying any energy saving measure concerning ventilation in these facilities, the HVAC system must still ensure the required positive air pressure and air movement from clean to less clean spaces. Nonetheless, during periods of non-occupation, the air change rate per hour $(\mathrm{ACH})$ may be decreased from the standardised values (Joppolo \& Romano, 2017). This reduction in the airflow rates to minimise energy use has been approached in the literature reviewed next. For hospitals or cleanrooms, Woods et al. (Woods, Reynolds, Montag, Braymen, \& Rasmussen, 1986) already proposed in 1986 manipulating ventilation control systems to reduce significant amounts of energy consumption in the operating rooms. Although modification of airflow rates needs a careful control, Gormley et al. (Gormley et al., 2017) concluded that not all parameters involving the number of particles and microorganisms directly improve when increasing the air renewals.

Wang et al. (Wang, Chang, Lai, \& Liu, 2012) also studied the HVAC system performance for an unoccupied operating room, seeking a compromise between energy savings and maintenance of the main operating room settings parameters. By particle and microbial counts, they concluded that reducing inlet airflow about $50 \%$ or more entailed noticeable energy savings without sacrificing air cleanliness, if positive air pressure is maintained with an overpressure above 1 Pa. In the same line, Porowski (Porowski, 2019) simulated two ventilation 
modes in an operating room: an "active mode", during operating activity and "passive mode" during non-occupation of the operating room, the latter reducing the outdoor airflow down to $30 \%$.

Finally, Castro Ruiz et al. (Castro Ruiz, San José Alonso, Villafruela Espina, \& Guijarro Rubio, 2011) defined the basis of operating room settings after service hours for Spanish hospitals, proposing the simultaneous reduction of inlet and outlet airflow up to $50 \%$ to guarantee differential pressure in the operating room.

Besides the existing literature on operating room, several researchers have focused on cleanrooms. Zhuang et al.(Zhuang, Wang, \& Shan, 2019) proposed a decoupled ventilation strategy to a cleanroom located in Hong Kong with an overall energy consumption of $21.64 \%$ less than that of the partially decoupled control strategy. Tschudi et al. (Tschudi, Faulkner, \& Hebert, 2005) studied two cleanrooms in periods of non-occupation and concluded that almost $30 \%$ of fan speed could be reduced at night, which represents a reduction of $72 \%$ in electric power consumption. They concluded that total savings of this strategy rise to $125 \mathrm{MWh}$ per year, without any adverse effect on the cleanliness state of the room. Loomans et al. (Loomans et al., 2019) analysed the energy savings achievable by applying three ventilation strategies in pharmaceutical cleanrooms, among which was the ventilation rate control based on demand. They demonstrated by particle concentration measuring that there was no source of contamination during unoccupancy. They obtained up to $93.6 \%$ savings in a monitored case study, through reduction, after 30 minutes of non-occupation, of the $\mathrm{ACH}$ to a minimum that maintained positive pressure.

\subsection{Contamination risks and applicable norms}

To avoid infection sources in operating rooms, HVAC systems work with large air changes with outdoor air from properly located and maintained intakes; then use high-efficiency particulate air filters (HEPA), preferably. Pressure differential permits prevention of contaminants entering from adjoining spaces, and a due design of flow patterns avoids dispersion of particles generated by patient care activities which can carry microorganisms and fungi (ASHRAE, 2019; Joppolo \& Romano, 2017). Particle concentration indoors is directly proportional to number of people, being due to skin peeling and particle release from clothing (D'Orazio, Galea, Maddaloni, \& Poggi, 2016) and air distribution is the key factor to reduce risks of cross infection (Berlanga et al., 2018). The absence of personnel during unoccupancy periods enables compliance with particle specifications under lower ventilation rates but positive air pressure (Loomans et al., 2019; Wang et al., 2012).

To avoid contamination risks, any action line regarding airflows in operating rooms must meet the exigences of the corresponding legislation on HVAC systems in hospitals. There are a number of related guides and standards worldwide. In Europe, current standards setting exigences to buildings HVAC systems still lack harmonisation (Pérez-Lombard, Ortiz, Coronel, \& Maestre, 2011) and, in particular for hospitals, the fact that each country has its own guides and legislation entails great difficulty to globalize the related standards.

Current applicable standards in Spain are UNE 100713:2005 (AENOR, 2005b) for the design and UNE 17134:2012 (AENOR, 2012) for validation of the systems, though both are about to be 
updated. Present settings distinguish three type of spaces in terms of risk level, while coming standards define five levels. Currently, either unidirectional or mixed flow operating rooms correspond to the most exigent level, for which the standard requires $15 \mathrm{~m}^{3} /\left(\mathrm{h} \cdot \mathrm{m}^{2}\right)$ minimum airflow per hour and unit floor area, as well as positive air pressure with $5 \mathrm{~Pa}$ indoor to outdoors overpressure. In coming standards, operating rooms will be reassigned as level 3, 4 or 5 , requiring $10 \mathrm{~Pa}, 15 \mathrm{~Pa}$ or $20 \mathrm{~Pa}$ overpressure, respectively. The corresponding classification in terms of indoor air cleanliness by particle concentration, according to the international standard (ISO14644-1, 2015), would be number 7 (Castro Ruiz et al., 2011).

\subsection{Scope of the work}

From the existing research reviewed, ventilation airflow control in operating rooms arises as a potential energy saving measure, which nonetheless must guarantee the maintenance of the indoor requirements.

This work proposes a setback ventilation, which consists in the reduction of the supplied airflow rates when the operating rooms are unoccupied. Positive air pressure is maintained by interrupting the return airflow. Setback control refers to any energy efficiency strategy consisting in a selective relieve of HVAC set-points during non-occupation or inactivity periods (Mathews, Botha, Arndt, \& Malan, 2001), being a proven energy efficiency measure for operating rooms in all climates (ASHRAE, 2019).

However, because setback ventilation implies absence of return airflow, it prevents any existing heat recovery system from operating. Consequently, it would only improve energy efficiency if it can introduce further savings than the existing heat recovery systems. The present study compares the energy, economic and emissions savings achievable through setback ventilation compared to a runaround coil loop heat recovery system. It also demonstrates that safety concerns are not affected.

This work approaches the above targets focusing on two case study-operating rooms in the University Clinical Hospital (HCU) of Valladolid, Spain. With this aim, it analyses: a) the maintenance of the overpressure inside the operating rooms; b) the lower demand of the HVAC system when operating either the heat recovery system or the setback mode; and, finally c) the yearly energy, economic and emissions savings achievable through setback during three scenarios of the operating rooms inactivity.

The following sections present the target case study and describe the tests performed. Later, section Results present the evolution of the overpressure indoors during the tests and the energy savings calculated. The actual applicability of these results and the expected impact are finally approached in the discussion section, in contrast to existing related research.

\section{Case study}

This study aims at improving the energy use related to the ventilation rates in the operating rooms of the University Clinical Hospital (HCU) of Valladolid, which is among the main public hospitals in the region of Castile and Leon, Spain. 
The HCU is an old building inaugurated in 1978, now under retrofitting works. Since 2019, heating is provided through the district heating with biomass of the University of Valladolid, whose power plant has 19.1 MW installed, having 31 public buildings connected in 2020.

The target operating rooms are in the new surgical area, built in 2013. The Heating, Ventilation and Air Conditioning (HVAC) systems at the HCU have a runaround loop heat recovery system. All operating rooms are certified yearly in terms of particle and CFU concentration to comply with the Spanish standard (AENOR, 2012). The characteristics of the operating room HVAC system are described next.

\subsection{Description of the HCU operating rooms}

The surgical area in the new emergency ward of the HCU has eighteen operating rooms, classified into two types depending on the ventilation distribution according to the current Spanish standards (AENOR, 2012), namely type A "unidirectional flow" and type B "mixed flow".

Among the available operating room, two were selected for the tests, one acting as a base case and the other implementing the proposed strategy. This enabled direct comparison of different operating performances under the same outdoor conditions. To minimize the influencing factors, the selected operating room should be similar in volume, type and functionality. The absence of external walls and the inactivity during the target periods, limited the thermal energy demand to ventilation loads, easing the study.

Considering the above requirements, operating rooms codified as OR1 and OR2 shown in Figure 1, both of type B, were selected for this study.

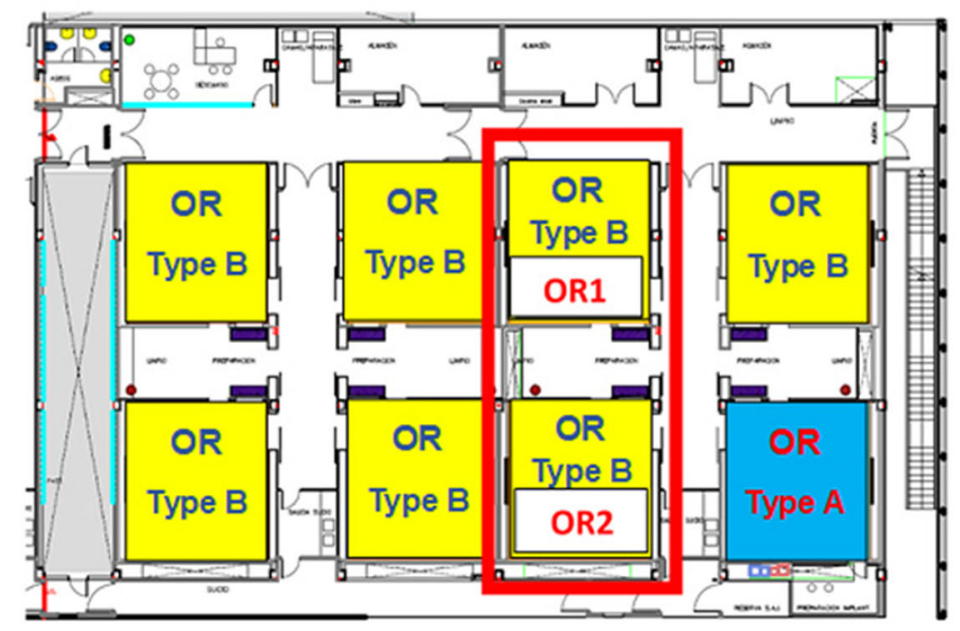

(a)

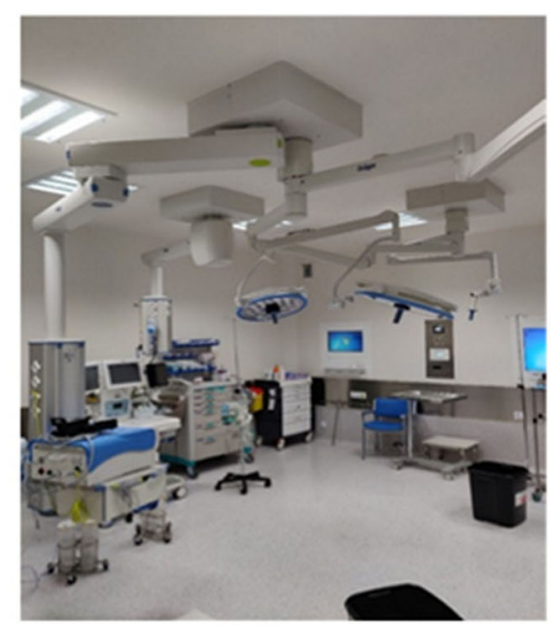

(b)

Figure 1: Target operating rooms OR1 and OR2 (a) within the surgical area and (b) view of OR1.

\subsection{Operating rooms HVAC systems}

Individual Air Handling Units (AHU) supply the ventilation demand at each operating room. These AHU are TROX Technik, controlled and monitored through a SCADA (Supervisory Control 
and Data Acquisition). Figure 2 describes the AHU of operating room OR1 on a view of its SCADA.

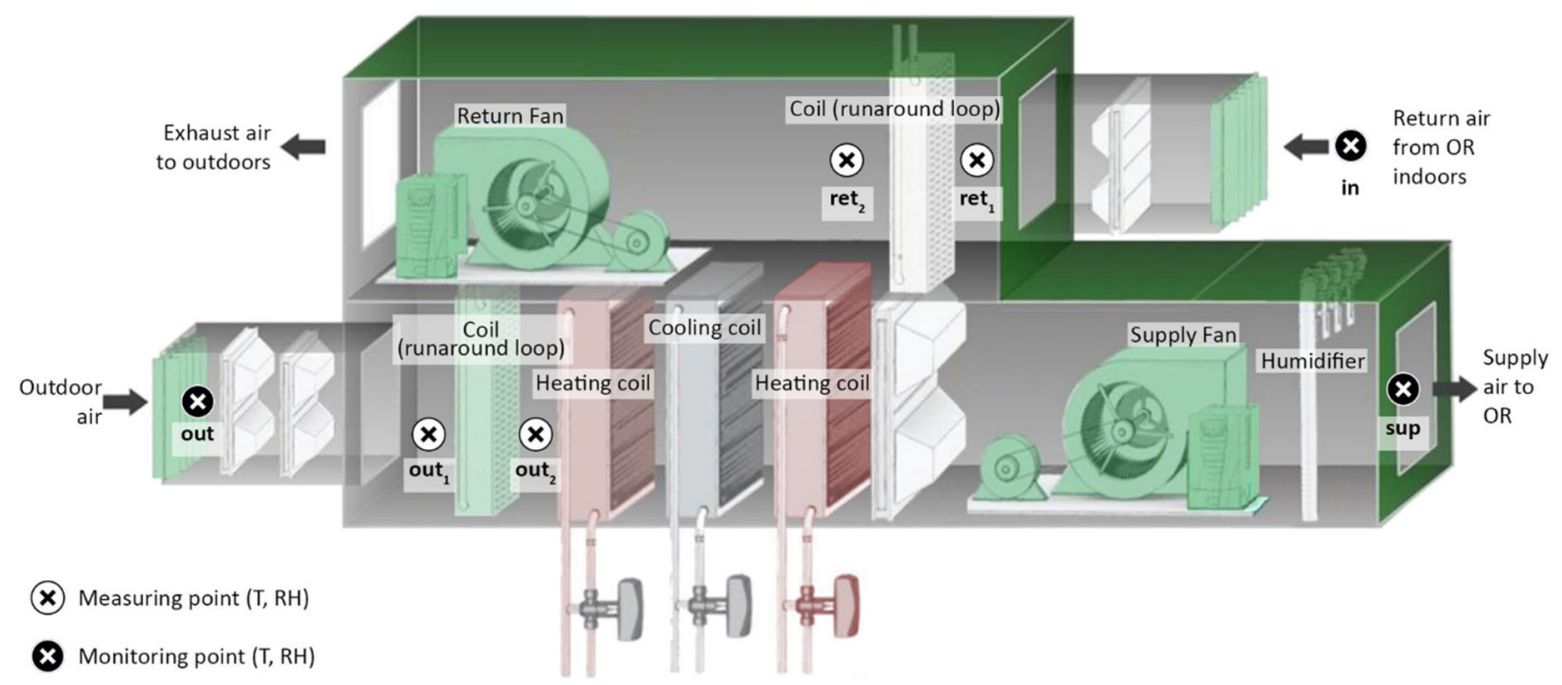

Figure 2: Scheme of the Air Handling Unit (TROX Technik) of the operating rooms.

Besides the due filters, silencers, etc., the conditioning stages at the AHUs consist of a heating and a cooling coils, steam humidification and a coil heat recovery (runaround) loop. The manufacturer provided the data necessary for the data analysis: the cooling coil works with water at $6 / 13^{\circ} \mathrm{C}$, cooling air from $33.2^{\circ} \mathrm{C}$ and $25.9 \% \mathrm{RH}$ to $12.7^{\circ} \mathrm{C}$ and $89.8 \% \mathrm{RH}$. The humidifier provides $17 \mathrm{~kg} / \mathrm{h}$ vapour. Finally, for the runaround loop, the value of the efficiency given is 0.47 under $3581 \mathrm{~kg} / \mathrm{h}$ outdoor air and $2723 \mathrm{~kg} / \mathrm{h}$ return air, with dry bulb temperatures at the inlet of $-5^{\circ} \mathrm{C}$ and $23^{\circ} \mathrm{C}$ for outdoor and return air, respectively. Definition of this efficiency corresponds to the European Standard (CEN, 1997) and is approached in detail later.

The SCADA permits real time monitoring of certain parameters, as well as control of some of them. Table 1 gathers these monitored and controlled parameters. Figure 3 represents the psychrometric evolutions for the AHU under the design conditions given in Table 1, for Winter and Summer outdoor design conditions of Valladolid.
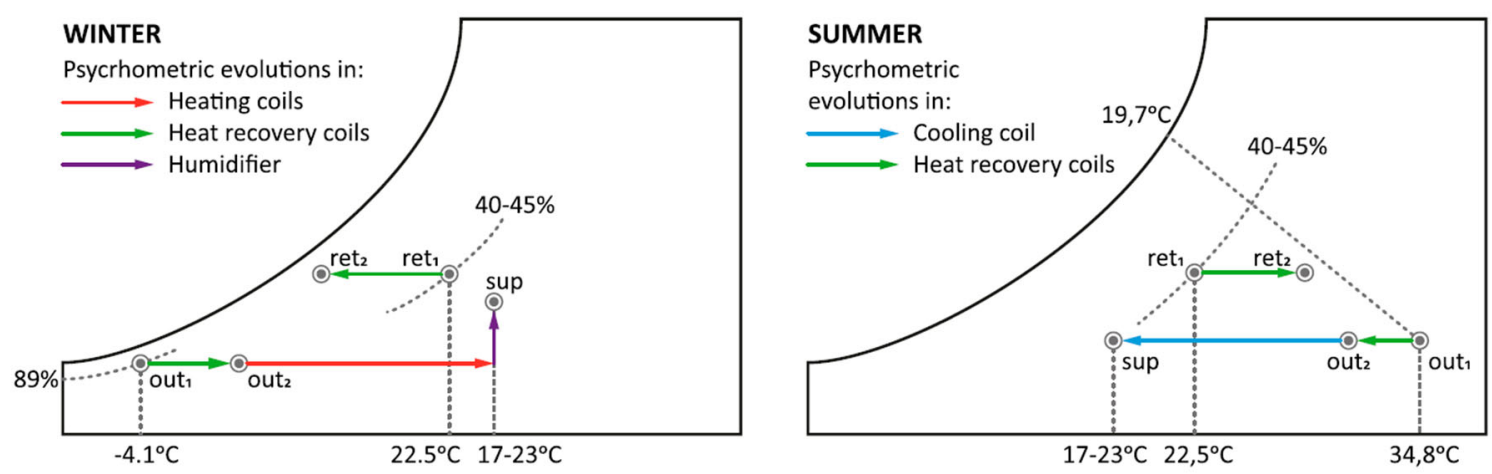

Figure 3: Design psychrometric conditions and evolutions for Valladolid in (a) Winter and (b) Summer.

A key parameter in this study is the overpressure maintained inside the operating room, which must meet the current standards revised in the introduction. As seen in Table 1, overpressure 
stablished at the operating room is $20 \mathrm{~Pa}$, while at the surgical preparation area and the corridor is 15 and $5 \mathrm{~Pa}$, respectively. These values are much above the present requirements, reaching the values established in the coming standards.

Table 1: Parameters monitored and controlled in the operating rooms.

\begin{tabular}{|c|c|c|}
\hline & Monitored parameters & $\begin{array}{l}\text { Settings for controlled } \\
\text { parameters }\end{array}$ \\
\hline \multirow{10}{*}{$\begin{array}{l}\text { AHU operating } \\
\text { conditions }\end{array}$} & Supply and return fan power (W) & - \\
\hline & Supply and return fan current (A) & - \\
\hline & Supply and return fan frequency $(\mathrm{Hz})$ & $\begin{array}{l}\text { Supply: } \min .50 \% \\
\text { Return: } \min .0-20 \%\end{array}$ \\
\hline & Supply and return fan rotational speed (rpm) & \\
\hline & Supply fan airflow rate $\left(\mathrm{m}^{3} / \mathrm{h}\right)$ & $2700 \mathrm{~m}^{3} / \mathrm{h}$ \\
\hline & Heating coil valve (\%) & - \\
\hline & Cooling coil valve (\%) & - \\
\hline & Humidifier (\%) & - \\
\hline & $\begin{array}{l}\text { Indoor temperature difference (from outdoors) for } \\
\text { runaround loop operation }\end{array}$ & $\pm 5^{\circ} \mathrm{C}$ \\
\hline & No frost control & $2^{\circ} \mathrm{C}$ \\
\hline \multirow{4}{*}{ Indoor conditions } & Dry Bulb Temperature $\left({ }^{\circ} \mathrm{C}\right)$ & $22.5^{\circ} \mathrm{C}$ \\
\hline & Relative Humidity (\%) & $40-45 \%$ \\
\hline & Enthalpy (kJ/kg) & - \\
\hline & Overpressure $(\Delta \mathrm{P})$ & $20 \mathrm{~Pa}$ \\
\hline \multirow{3}{*}{ Supply conditions } & Dry Bulb Temperature $\left({ }^{\circ} \mathrm{C}\right)$ & $\begin{array}{l}\text { Min. } 17.0^{\circ} \mathrm{C} \\
\text { Max. } 23.0^{\circ} \mathrm{C}\end{array}$ \\
\hline & Relative Humidity (\%) & - \\
\hline & Airflow rate $\left(\mathrm{m}^{3} / \mathrm{h}\right)$ & - \\
\hline \multirow{3}{*}{ Outdoor conditions } & Dry Bulb Temperature $\left({ }^{\circ} \mathrm{C}\right)$ & - \\
\hline & Relative Humidity (\%) & - \\
\hline & Enthalpy (kJ/kg) & - \\
\hline
\end{tabular}


Bidirectional ventilation (fan assisted air volume flow in both direction, supply and exhaust (CEN, 2017)) permits this overpressure, where supply airflow is maintained while return fan adjusts to maintain the desired pressure difference from the outside areas. Besides, it enables the installation of a heat recovery system. The type of heat exchanger installed (coil runaround loop) avoids any risk of leakage between airflows. The runaround heat exchanger operates when the temperature drop between outdoor and return air flows is at least $\pm 5^{\circ} \mathrm{C}$. This value is fixed in the control settings of the AHU.

\section{Methodology}

This section describes the strategy proposed and presents the tests performed at the target hospital HCU. Then, describes how the data obtained was analysed and the estimation procedure to extend the study to the whole year. Comparison of real and estimated data validated the estimated procedure and enabled the evaluation in the next section of the setback feasibility.

\subsection{Ventilation strategy}

The alternative ventilation strategy proposed for the operating rooms based in differentiating between periods of occupation and non-occupation, being the latter less restrictive, according to the Spanish Standard (AENOR, 2005b). During occupation, supply air flow rate (V'_sup) was kept constant at $2700 \mathrm{~m}^{3} / \mathrm{h}$, implying about 21.8 air changes per hour (ACH), while overpressure was maintained through the return fan frequency converter. If unoccupied, supply air flow could diminish to a setback airflow rate ( $\mathrm{V}$-_setback) of $1350 \mathrm{~m}^{3} / \mathrm{h}$, while return fan stopped to ensure the required overpressure indoors. The existing system is equipped with non-return dampers and a set of alarms that prevent from overpressure drop, excessive humidity or temperature indoors besides alarms for filter saturation, fire, etc.

According to the revision made in the introduction, lack of indoor overpressure would be the only possible source of contamination when the operating rooms remain unoccupied. Consequently, to avoid risks of infection, the study checks that setback ventilation strategy does not hinder the positive air pressure required indoors.

On the other hand, because this setback implies fan assisted flow of only supply air, it prevents the runaround loop from recovering heat. Consequently, analysing the energy savings required a careful study of the operating conditions in each case.

\subsection{Tests performed}

Data used in this work belongs to both monitored and measured parameters. Tests performed, data acquired, and target parameters are described in Figure 4.

Tests targeted two final objectives: (a) checking that indoor overpressure maintained at safe levels during setback and (b) evaluate the energy savings achievable. 


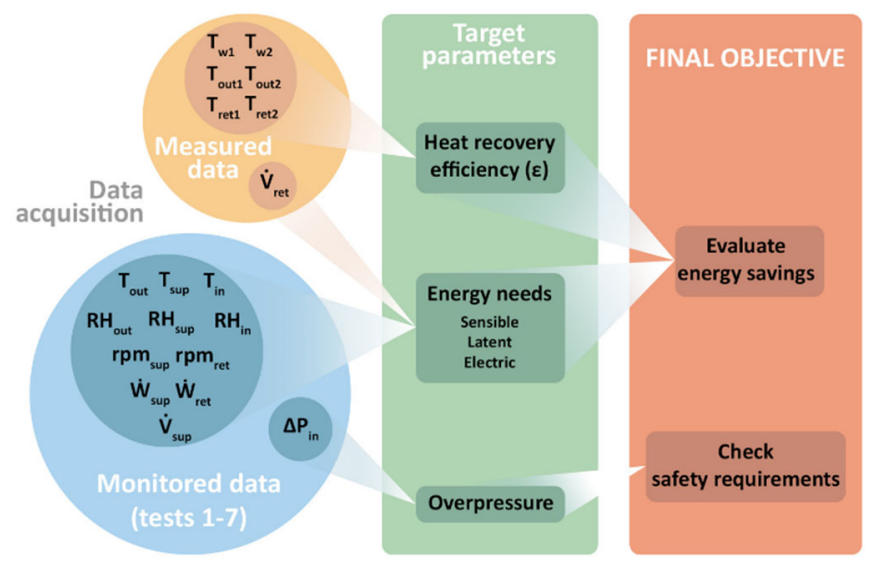

Figure 4: Scheme of the tests performed, parameters sought and objectives.

Table 2 describes the monitored tests. Except for test 2, which belonged to working days, the remaining corresponded to weekends, when the HCU managers gave permission to implement the setback strategy. The first two tests were performed with only OR2 available; consequently, Test 2 under "normal" ventilation mode was not performed simultaneously but immediately after Test 1 , along the whole working week. The SCADA provided data each 10 minutes.

Table 2: Monitoring tests performed at the HCU.

\begin{tabular}{|c|c|c|c|c|c|c|}
\hline \multirow{2}{*}{ Test } & \multirow{2}{*}{ Month } & \multicolumn{2}{|c|}{ Period } & \multirow{2}{*}{ Duration (h) } & \multirow{2}{*}{ Ventilation mode } & \multirow{2}{*}{$\begin{array}{l}\text { Operating } \\
\text { room }\end{array}$} \\
\hline & & Begin & End & & & \\
\hline 1 & March & $22 / 03 / 2019$ & 25/03/2019 & 60 & Setback & OR2 \\
\hline 2 & March & $25 / 03 / 2019$ & 29/03/2019 & 108 & Normal & OR2 \\
\hline 3 & May & $17 / 05 / 2019$ & 20/05/2019 & 60 & Normal/Setback & OR1/ OR2 \\
\hline 4 & July & $26 / 07 / 2019$ & 29/07/2019 & 60 & Normal/Setback & OR1/ OR2 \\
\hline 5 & August & $16 / 08 / 2019$ & 19/08/2019 & 53 & Normal/Setback & OR1/ OR2 \\
\hline 6 & December & $7 / 12 / 2019$ & $10 / 12 / 2019$ & 60 & Normal/Setback & OR1/ OR2 \\
\hline 7 & January & $17 / 01 / 2020$ & 20/01/2020 & 60 & Normal/Setback & OR1/ OR2 \\
\hline
\end{tabular}

The measurements performed on the runaround loop consisted on four dry bulb temperature (T) and relative humidity (RH) sensors Testo $175 \mathrm{HI}$ placed at the air inlet (1) and outlet (2) of the coils in both the outdoor (out) and return (ret) airflows; besides two temperature sensors Testo $175 T 2$ measuring the water temperatures (TW) in the loop and the ambient temperatures. Sensors Testo $175 \mathrm{H} 1$ have range $-20 /+55^{\circ} \mathrm{C}$ with accuracy $\pm 0.4^{\circ} \mathrm{C}$ for dry bulb temperature, while for Relative Humidity range is $0 / 100 \%$ with accuracy $\pm 2 \%$ for $\mathrm{RH}$ from 2 to $98 \%$ at $25^{\circ} \mathrm{C}$. All sensors were calibrated before their installation. Sensors Testo $175 T 2$ measuring water temperatures have a range $-40 /+120^{\circ} \mathrm{C}$ with accuracy $\pm 0.3^{\circ} \mathrm{C}$, while temperature sensors measuring ambient air have range $-35 /+55^{\circ} \mathrm{C}$ with accuracy $\pm 0.5^{\circ} \mathrm{C}$. 
Finally, the measurements to characterise the return airflow ( $V$ 'ret) were necessary because continuous measurements and monitoring were available only for the supply airflow. However, the SCADA provides data on the electric power, current, frequency and rotational speed of both fans. Measuring the return airflow enabled its relation to the monitored parameters of the fan. With this purpose, air velocities were measured on a matrix with a hot wire anemometer Testo 06351535 , with range $0-20 \mathrm{~m} / \mathrm{s}$ and accuracy $\pm 0.03 \mathrm{~m} / \mathrm{s}+4 \%$ of the measured value. Values for the return airflow were then compared to the available information from the certification of the operating rooms.

\subsection{Data analysis}

The study first analysed the monitored results during Tests 1 to 7 ; then estimated these results based on the Typical Meteorological Year (TMY) weather data for the same periods of Tests 1 to 7, together with the setpoint values given in Table 1. Comparison between the estimated results and the actual ones enabled validation of the estimation procedure. Once validated, this estimation was broadened to the whole TMY to provide figures of the energy and economic savings achievable through setback ventilation in the operating rooms.

Along the duration of each monitored test, there was availability through the SCADA to all parameters listed in Table 1. The operating conditions registered by the SCADA provided all the variables needed for the study, while the unknown psychrometric variables derived from the well-known equations for humid air (ASHRAE, 2017).

As indicated before, setback strategy proposed does not permit the existing runaround loop to operate. On the other hand, when studying the thermal energy demand, the setback strategy reduces both to the sensible $\left(\dot{Q}_{s}\right)$ and latent $\left(\dot{Q}_{L}\right)$ energy loads with the lower airflow rates, while the runaround loop only enables the AHU to recover sensible heat. Finally, it must be remembered that the setpoint for the runaround loop operation, fixed in the SCADA, is an absolute temperature difference between outdoor $\left(T_{\text {out }}\right)$ and return $\left(T_{\text {ret }}\right)$ air above $5^{\circ} \mathrm{C}$. Considering these three facts, the study of the thermal energy savings achievable through the strategy proposed compared to the present situation was as follows.

The sensible heat savings were obtained as:

$$
\dot{Q}_{\text {s savings }}=\left(\dot{Q}_{\text {s demand }}-\dot{Q}_{\text {s recovered }}\right)-\dot{Q}_{\text {s setback }}
$$

Where the sensible heat demand to condition outdoor air to supply conditions ( $T_{\text {sup }}$ ) was:

$$
\dot{Q}_{\text {sdemand }}=\frac{\dot{V}_{\text {sup }}}{v_{\text {sup }}} \cdot\left[c_{\text {p ma }} \cdot\left(T_{\text {sup }}-T_{\text {out }}\right)\right]
$$

Being $v_{\text {sup }}$ the specific volume $\left(\mathrm{m}^{3} / \mathrm{kg}\right)$ of air in supply conditions and $c_{p M A}$ the specific heat of moist air $\left(\mathrm{kJ} /\left(\mathrm{kg}^{\circ} \mathrm{C}\right)\right)$.

While the sensible heat demand under setback ventilation was:

$$
\dot{Q}_{\text {s setback }}=\frac{\dot{V}_{\text {setback }}}{v_{\text {sup }}} \cdot\left[c_{p m a} \cdot\left(T_{\text {sup }}-T_{\text {out }}\right)\right]
$$

If the temperature difference between outdoor and return air is above $5^{\circ} \mathrm{C}$ (runaround loop operating), the sensible heat recovered was: 


$$
\dot{Q}_{\text {srecovered }}=\frac{\dot{V}_{\text {out }}}{v_{\text {out }}} \cdot c_{\text {pma }} \cdot\left(T_{\text {out } 2}-T_{\text {out } 1}\right)
$$

Being $v_{\text {out }}$ the specific volume $\left(\mathrm{m}^{3} / \mathrm{kg}\right)$ of air in outdoor conditions. Air temperature at the primary airstream coil inlet, $T_{\text {out } 1}$, was that of outdoor air, whereas air temperature at the outlet of this same coil (Tout 2) was calculated through the efficiency determined in the tests. The European Standard (CEN, 1997) defines this efficiency as:

$$
\varepsilon=\frac{T_{\text {out } 2}-T_{\text {out } 1}}{T_{\text {ret } 1}-T_{\text {out } 1}}
$$

However, if the temperature difference between outdoor and return air was below $5^{\circ} \mathrm{C}$ (runaround loop non-operating), there was no heat recovered:

$$
\dot{Q}_{\text {s recovered }}=0
$$

During non-occupation periods, the only latent loads were due to ventilation. Consequently, humidification or dehumidification needs depended only on the outdoor air conditions. In the AHU studied (Figure 1), where no controlled dehumidification is possible, the following situations can take place:

- During heating needs: (a) there is no need for humidification or (b) humidification is necessary to reach indoor design conditions.

- During cooling needs: (a) there is no uncontrolled dehumidification nor humidification needs; (b) there is no uncontrolled dehumidification but humidification is required; (c) uncontrolled dehumidification in the cooling coil occurs, but no humidification to reach indoor conditions is required; and (d) both uncontrolled dehumidification and subsequent humidification occur.

In the target climate, humidification will be presumably necessary under heating needs; whereas, during cooling season, uncontrolled dehumidification is improbable (see Figure 3). Nonetheless, the analysis proposed here covered the general case, where all possible situations in the target AHU could occur.

Situation (a) involves no latent loads. For all the rest, provided that the runaround loop operated or not, latent heat savings were:

$$
\dot{Q}_{L \text { savings }}=\dot{Q}_{L \text { demand }}-\dot{Q}_{L \text { setback }}
$$

If there was only humidification, either during heating or cooling season (situation (b)), the latent load to condition outdoor air was:

$$
\dot{Q}_{L \text { demand }}=\frac{\dot{V}_{\text {sup }}}{v_{\text {sup }}} \cdot\left[c_{L} \cdot\left(w_{\text {sup }}-w_{\text {out }}\right)\right]
$$

Where $w_{\text {sup }}$ and $w_{\text {out }}$ are the specific humidity $(\mathrm{kg} / \mathrm{kg})$ of supply and outdoor air, respectively; whereas $c_{L}$ is the latent heat of water $(\mathrm{kJ} / \mathrm{kg})$.

Under setback ventilation, it was:

$$
\dot{Q}_{L \text { setback }}=\frac{\dot{V}_{\text {setback }}}{v_{\text {sup }}} \cdot\left[c_{L} \cdot\left(w_{\text {sup }}-w_{\text {out }}\right)\right]
$$


During cooling season, if outdoor air dew point temperature exceeded the operating temperature of the cooling coil, then dehumidification occurred. In this case (situation (c) and (d)), there existed latent load due to condensation:

$$
\dot{Q}_{L}=\frac{\dot{V}_{\text {sup }}}{v_{\text {sup }}} \cdot\left[c_{L} \cdot\left(w_{c c 2}-w_{c c 1}\right)\right]
$$

Where $w_{c c 1}$ and $w_{c c 2}$ are the specific humidity at the inlet and outlet of the cooling coil. The former can be either that of the runaround coil outlet or that of outdoor air, provided that the runaround operated or not. The latter was obtained through the information provided by the manufacturer, as:

$$
w_{c c 2}=w_{c}+F_{B P} \cdot\left(w_{c c 1}-w_{c}\right)
$$

Being $F_{B P}$ the coil Bypass factor (0.07) and $w_{c}$ the specific humidity of air in contact with the coil surface. The latter corresponded to air saturation at the coil temperature, which would be close to the water temperature inside. Design temperatures for water were $6^{\circ} \mathrm{C}$ at the inlet and $13^{\circ} \mathrm{C}$ at the outlet.

In the last situation (d), when uncontrolled dehumidification occurred and additional humidification was necessary to reach the supply setpoint conditions, latent load due to this additional humidification was:

$$
\dot{Q}_{L}=\frac{\dot{V}_{\text {sup }}}{v_{\text {sup }}} \cdot\left[c_{L} \cdot\left(w_{\text {sup }}-w_{c c 2}\right)\right]
$$

Under setback ventilation, previous equations (E-9) and (E-11) considered setback airflow instead of supply.

Finally, setback ventilation strategy also aims at reducing the electric energy needs of fans. Because there is no by-pass of the runaround loop system no matter it operates or not, the pressure loss coefficient of the whole system is constant. Consequently, the electric energy required by the fans depends only on the airflow rate. The setback strategy can thus introduce large energy savings, based in reducing the supply airflow to half the ventilation rate imposed and stopping the return air fan. As indicated in table 1, the SCADA registers all parameters of both the supply and return fans. In addition to these savings due to airflow decrease, setback also avoids the electric energy consumption to run the water pump of the runaround loop.

\subsection{Data estimation}

To extend the study beyond the test periods, it was necessary to provide a methodology to estimate results. Comparison of estimated and actual results during the tests gave evidence of the estimation adequacy.

Estimation of the previously described sensible and latent loads based on the following assumptions:

- Outdoor conditions were that of the TMY of Valladolid.

- Return air was at the average indoor design conditions (Table 1).

- Return airflow from the operating room was extracted at a constant rate of $1350 \mathrm{~m}^{3} / \mathrm{h}$ under "normal" ventilation and was zero during setback. 
- Airflow to the operating room was supplied at a constant rate of $2700 \mathrm{~m}^{3} / \mathrm{h}$ and $1350 \mathrm{~m}^{3} / \mathrm{h}$ under "normal" and setback ventilation, respectively.

- Supply air temperature was at the upper limit in Winter and at the lower limit in Summer (Table 1).

- Rate of vapor injection at the humidifier was $\dot{m}_{v}=17 \mathrm{~kg} / \mathrm{h}$ (information provided by the manufacturer).

The last two suppositions enabled prediction of the specific humidity of supply air under the four possible cases of humidification and/or dehumidification.

When neither uncontrolled dehumidification occurs, nor humidification was required (situation (a)), the specific humidity of supply air was that of outdoor air.

If only humidification exists (situation (b)), it was:

$$
w_{\text {sup }}=w_{\text {out }}+\dot{m}_{v} \cdot \frac{\dot{V}_{\text {sup }}}{v_{\text {sup }}}
$$

When uncontrolled dehumidification occurs but no consequent humidification is required (situation (c)), supply air specific humidity wwas:

$$
w_{\text {sup }}=w_{c c 2}=w_{c}+F_{B P} \cdot\left(w_{\text {out }}-w_{c}\right)
$$

In the last possible situation (d), both uncontrolled dehumidification and humidification existed. Hence:

$$
w_{\text {sup }}=w_{c}+F_{B P} \cdot\left(w_{\text {out }}-w_{c}\right)+\dot{m}_{v} \cdot \frac{\dot{V}_{\text {sup }}}{v_{\text {sup }}}
$$

An additional hypothesis needed to be made to determine the specific volume of supplied air, as it depends on the humidity of moist air. At the altitude of Valladolid (700 meters above sea level), its value would range from $0.899 \mathrm{~m}^{3} / \mathrm{kg}$ at the lower limit of the supply temperature $\left(17^{\circ} \mathrm{C}\right)$ at a low relative humidity $(30 \%)$ to $0.932 \mathrm{~m}^{3} / \mathrm{kg}$ at the upper limit of the supply temperature $\left(23^{\circ} \mathrm{C}\right)$ at a high supply relative humidity $(70 \%)$. Given this negligible variation, estimations were made for a constant $\mathrm{v}_{\text {sup }}=0.9 \mathrm{~m}^{3} / \mathrm{kg}$.

Actual operating periods of the humidifier were deduced from the data given by the SCADA, but the estimated periods needed to base on the setpoints of the indoor relative humidity ( $\mathrm{RH}$ in) (table 1). Humidification was considered when outdoor specific humidity ( $w_{\text {out }}$ ), for the indoor dry bulb temperature set point $\left(T_{i n}\right)$, resulted into indoor relative humidity below the lower setpoint limit $40 \%$.

$$
R H\left(w_{\text {out }}, T_{\text {in }}\right)<40 \%
$$

Uncontrolled dehumidification was considered when outdoor air dew point temperature, from TMY data, was above the average value of water temperatures in the cooling coil described in previous (E-10). If uncontrolled dehumidification occurred, subsequent humidification was required if:

$$
R H\left(w_{c c 2}, T_{i n}\right)<40 \%
$$

Again, the unknown psychrometric variables were obtained from the equations for humid air (ASHRAE, 2017). 


\section{Results}

The first approach to the tests was the validation that overpressure maintained indoors during the setback strategy remained at the desired level. Then, once the strategy was acceptable in terms of indoor contamination avoidance, actual and predicted results were analysed to determine the energy savings achievable.

\subsection{Overpressure levels}

First, results were analysed to check that operating rooms maintained a positive air pressure, being the overpressure at least $5 \mathrm{~Pa}$ to outdoors. No matter the operating room operated under normal or setback ventilation mode, there were punctual drops in the overpressure registered. These were due to door opening, which immediately reduces the pressure differential between connected areas (ASHRAE, 2019). During the tests, door opening could occur for cleaning or maintenance purposes. Table 3 gathers the average, standard deviation, minimum, percentage of nonconforming values and average of nonconforming values of the overpressure during the tests. Overpressure values were considered nonconforming when they became lower than 5 Pa accepted in the current standards (AENOR, 2005b). Tests 3 and 6 for OR1 under normal ventilation mode did not present any nonconforming value.

Table 3. Overpressure values maintained inside the target operating room during the tests.

\begin{tabular}{|c|c|c|c|c|c|c|}
\hline Test & Operating room & $\begin{array}{c}\text { Average } \\
\text { overpressure } \\
\text { (Pa) }\end{array}$ & $\begin{array}{l}\text { Overpressure } \\
\text { standard } \\
\text { deviation } \\
(\mathrm{Pa})\end{array}$ & $\begin{array}{l}\text { Nonconforming } \\
\text { values (\%) }\end{array}$ & $\begin{array}{c}\text { Average } \\
\text { nonconforming } \\
\text { values }(\mathrm{Pa})\end{array}$ & $\begin{array}{l}\text { Minimum } \\
\text { value }(\mathrm{Pa})\end{array}$ \\
\hline 1 & OR2 (setback) & 17.9 & 3.7 & $3.1 \%$ & 1.2 & 0.3 \\
\hline \multirow[t]{2}{*}{2} & OR2 (normal) & 19.7 & 7.7 & $11.3 \%$ & 0.7 & 0.2 \\
\hline & OR1 (normal) & 22.8 & 1.1 & $0.0 \%$ & na & 19.9 \\
\hline \multirow{2}{*}{3} & OR2 (setback) & 19.4 & 2.7 & $1.7 \%$ & 1.2 & 0.3 \\
\hline & ORI (normal) & 3.1 & 7.3 & $86.0 \%$ & 0.2 & 0.1 \\
\hline \multirow{2}{*}{4} & OR2 (setback) & 15.6 & 4.6 & $2.6 \%$ & 1.9 & 0.2 \\
\hline & OR1 (normal) & 18.2 & 8.2 & $16.0 \%$ & 0.2 & 0.1 \\
\hline \multirow{2}{*}{5} & OR2 (setback) & 17.9 & 6.2 & $10.4 \%$ & 0.4 & 0.2 \\
\hline & OR1 (normal) & 20.2 & 1.2 & $0.0 \%$ & na & 17.8 \\
\hline \multirow{2}{*}{6} & OR2 (setback) & 14.1 & 7.6 & $22.5 \%$ & 0.4 & 0.2 \\
\hline & OR1 (normal) & 18.9 & 4.6 & $5.6 \%$ & 0.6 & 0.1 \\
\hline 7 & OR2 (setback) & 13.2 & 8.2 & $27.8 \%$ & 0.4 & 0.1 \\
\hline
\end{tabular}


Test 4 under normal ventilation registered a long period with a loss of overpressure. After maintenance and cleaning activities, the door at ORI was not properly closed. This fact illustrated that undesirable, though hardly avoidable, situations may occur independently of the ventilation mode.

Figure 5 presents the evolution of the overpressure during normal or setback operation implemented in tests 1 and 2. As can be derived from results in table 3, this graph is illustrative of the remaining tests.

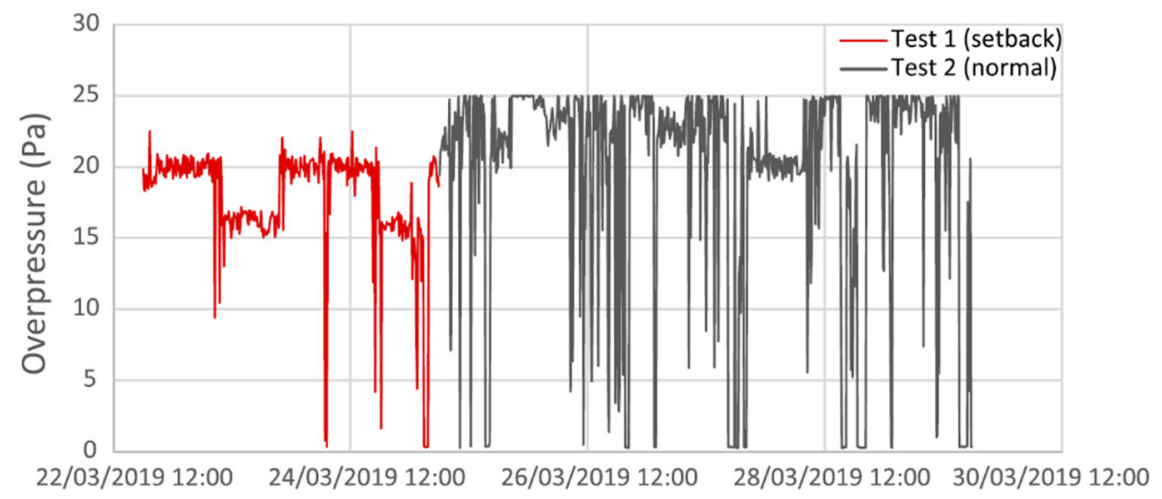

Figure 5. Overpressure evolution inside OR2 during test 1 (setback ventilation) and then test 2 (normal ventilation).

These findings showed that overpressure would maintain much above the limits established in the standards, only dropping to unacceptable values due to unavoidable causes not related to the ventilation mode. In the absence of actual measurements on particles and CFUs concentrations, overpressure gives evidence of preventing the entrance of contaminants from adjacent spaces. Together with the appropriate filtering of clean, outdoor air, during nonoccupation of the operating rooms it can thus be assumed that the indoor air quality level is maintained as established for the corresponding classification of the operating room.

This conclusion is valid for both mixed and unidirectional flow operating rooms available at the $\mathrm{HCU}$, because both operating room types were subject to the same overpressure requirements according to the current standard, as reviewed in the introduction. It would also be acceptable in the near future because both operating room types in the HCU will be reclassified as "type 4" in the coming standard, requiring 15 Pa indoor overpressure.

\subsection{Electric power requirements of fans}

As explained in the methodology section, the electric energy required by the fans depends only on the airflow rate. The SCADA provided data of the electric power for both supply and return fan but gave only the supply airflow (Table 1). This made necessary the measuring of the return airflow, as described in the previous section.

The average electric power required by the supply fan at about $2700 \mathrm{~m}^{3} / \mathrm{h}$ and $1350 \mathrm{~m}^{3} / \mathrm{h}$ was $1.5 \mathrm{~kW}$ and $0.28 \mathrm{~kW}$, respectively. For the return fan, return airflow of about $1350 \mathrm{~m}^{3} / \mathrm{h}$ corresponded to $0.42 \mathrm{~kW}$. Power of the water pump of the coil heat recovery (runaround) loop was $0.21 \mathrm{~kW}$ at $2700 \mathrm{l} / \mathrm{min}$. 


\subsection{Efficiency of the runaround loop}

Figure 6 shows the efficiency of the runaround loop $(\varepsilon)$ calculated from equation $(E-5)$ for the measured operating conditions, in terms of temperature difference between both operating airflows at the corresponding coils inlet. A slightly decreasing trend with the temperature difference can be observed, due to the same definition of the system efficiency (equation E5). Indeed, efficiency of the system maintained at about 0.4. Although this is a lower value than the one provided by the manufacturer given in the case study section, the latter corresponded to a smaller difference between supply and return airflows.

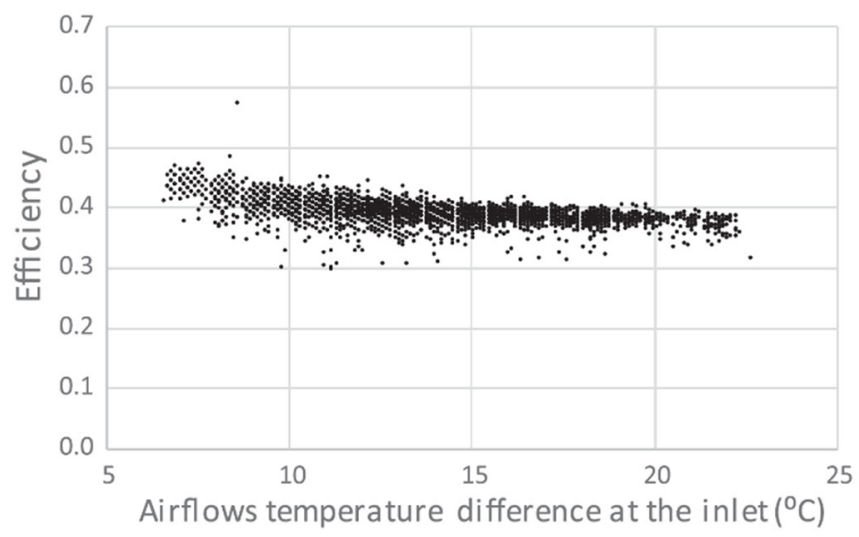

Figure 6. Efficiency measured in the coil heat recovery runaround loop

A linear least squares regression applied to data shown in Figure 6 yielded the following equation, used for the calculations in this work:

$$
\varepsilon=0.4458-0.0035 \cdot\left(T_{\text {ret } 1}-T_{\text {out } 1}\right)
$$

\section{Actual and predicted energy savings}

As explained in the case study section, ventilation is the only source of energy needs in the target operating room during non-occupation periods. Setback can yield substantial thermal energy savings due to the reduction in the ventilation rate, besides electric savings from the lower requirements of the supply fan and the non-operation of the return fan.

Table 4 shows, for each test described in table 2, the estimated and real values for the heating and cooling degree hours (HDH, CDH).

Table 4. Actual and estimated hygrothermal needs during the tests.

\begin{tabular}{|c|c|c|c|c|c|c|c|c|c|c|c|c|}
\hline \multirow{2}{*}{$\begin{array}{c}\text { Test } \\
\text { Values }\end{array}$} & \multicolumn{2}{|c|}{1} & \multicolumn{2}{|c|}{3} & \multicolumn{2}{|c|}{4} & \multicolumn{2}{|c|}{5} & \multicolumn{2}{|c|}{6} & \multicolumn{2}{|c|}{7} \\
\hline & Estim. & Real & Estim. & Real & Estim. & Real & Estim. & Real & Estim. & Real & Estim. & Real \\
\hline $\mathrm{HDH}$ & 852 & 880 & 550 & 630 & 217 & 207 & 61 & 30 & 1201 & 983 & 985 & 1000 \\
\hline $\mathrm{CDH}$ & 0 & 0 & 2 & 0 & 123 & 37 & 100 & 194 & 0 & 0 & 0 & 0 \\
\hline $\begin{array}{l}\text { Humidification } \\
\text { requirements period (\%) }\end{array}$ & $100 \%$ & $100 \%$ & $100 \%$ & $100 \%$ & $54 \%$ & $34 \%$ & $40 \%$ & $39 \%$ & $100 \%$ & $100 \%$ & $100 \%$ & $96 \%$ \\
\hline $\begin{array}{l}\text { Dehumidification } \\
\text { requirements period (\%) }\end{array}$ & $0 \%$ & $0 \%$ & $0 \%$ & $0 \%$ & $0 \%$ & $53 \%$ & $19 \%$ & $41 \%$ & $0 \%$ & $0 \%$ & $0 \%$ & $0 \%$ \\
\hline
\end{tabular}


Periods for humidification needs derived from applying the same equation (E-12), while outdoor specific humidity resulting into indoor RH above upper setpoint limit $45 \%$ indicated that dehumidification may be needed (E-14):

$$
R H\left(w_{\text {out }}, T_{\text {in }}\right)>45 \%
$$

This enabled comparison of the actual climate conditions having occurred during the tests and the predicted ones through the TMY.

Valladolid has a temperate climate with dry, warm summers (Csb according to the KoppenGeiger classification) (Tejero-González, Andrés-Chicote, García-lbáñez, Velasco-Gómez, \& Rey-Martínez, 2016). Consequently, there are heating needs from September to May. Tests 7 , 1, 3 and 6 belonged to this period, while July and August (tests 4 and 5) had cooling needs. Real HDH were larger than the estimated for tests during heating period, except for test 6 . Also, real CDH during cooling needs of Test 5 were larger, though Test 6 showed the opposite. This demonstrated that, in general, the TMY is milder than the real conditions, as expected. Exceptions for tests 6 (December) and specially test 4 (July) were due to unusually mild real climate conditions registered.

Table 5 gathers the energy demand and savings achieved through the coil heat recovery (runaround) loop and the setback strategy. It does not include test 2 because it only implemented normal ventilation mode.

Tests 7, 1, 3 and 6 (January, March, May and December, respectively) were heating demanding. This corresponds to the expected results for Valladolid (Csb climate). There were cooling needs during test 3 (May), yet negligible. Heating needs during summer must be supplied, because during non-occupation period thermal loads at the operating room are only due to ventilation and the indoor conditions must be maintained to ensure the operating room to be prepared for possible use. Energy recovered by the runaround loop coil varied between 42 to $69 \%$, below results in the literature for similar climates (Kassai, Poleczky, Al-Hyari, Kajtar, \& Nyers, 2018).

Savings achievable through setback always exceed those achievable by the existing heat recovery system, except for heating needs during test 4 , due to the unusual climate conditions. Although this is less noticeable for heating, setback savings more than double those of runaround loop under cooling needs.

Conditions for the same months of tests 1, 3, 6 and 7 implied humidification during the whole period. However, real operating periods of the humidifier in tests 1 and 7 were much shorter. Having a closer look to the registered values, these tests showed long periods when the humidifier was blocked. The maintenance stuff informed that this situation sometimes happened due to the limited life of the RH control sensors.

In general, predicted savings for the runaround loop and the setback strategy did not exceed real results. This ensured predicted results to not overestimate the savings achievable. Although tests 4 and 6 provided estimated savings over actual values, it was due to the unusually mild conditions occurred during these tests observed in table 4 . 
ENERGY USE OPTIMIZATION IN VENTILATION OF OPERATING ROOMSDURING INACTIVITY PERIODS

Table 5. Energy demand and savings achieved through the different strategies.

\begin{tabular}{|c|c|c|c|c|c|c|c|c|c|c|c|c|}
\hline Test & \multicolumn{2}{|c|}{1} & \multicolumn{2}{|c|}{3} & \multicolumn{2}{|c|}{4} & \multicolumn{2}{|c|}{5} & \multicolumn{2}{|c|}{6} & \multicolumn{2}{|c|}{7} \\
\hline Values & Estim. & Real & Estim. & Real & Estim. & Real & Estim. & Real & Estim. & Real & Estim. & Real \\
\hline \multicolumn{13}{|l|}{ Sensible energy - HEATING } \\
\hline Demand (kWh) & 594.8 & 643.9 & 352.8 & 463.0 & 110.7 & 53.5 & 9.7 & 2.4 & 889.5 & 746.9 & 708.4 & 641.7 \\
\hline Runaround operating period (\%) & $100 \%$ & $100 \%$ & $73 \%$ & $97 \%$ & $40 \%$ & $24 \%$ & $0 \%$ & $0 \%$ & $100 \%$ & $100 \%$ & $100 \%$ & $100 \%$ \\
\hline Runaround loop savings (kWh) & 283.0 & 301.4 & 176.5 & 209.5 & 63.9 & 37.0 & 0.0 & 0.0 & 381.5 & 316.2 & 322.9 & 330.4 \\
\hline Setback savings (kWh) & 297.4 & 321.4 & 176.4 & 231.6 & 55.4 & 26.7 & 4.8 & 1.2 & 444.8 & 372.9 & 354.2 & 336.8 \\
\hline \multicolumn{13}{|l|}{ Sensible energy - COOLING } \\
\hline Demand (kWh) & 0.0 & 0.2 & 13.6 & 0.0 & 158.5 & 149.6 & 156.3 & 302.9 & 0.0 & 0.0 & 0.0 & 0.0 \\
\hline Runaround operating period (\%) & $0 \%$ & $0 \%$ & $0 \%$ & $0 \%$ & $22 \%$ & $1 \%$ & $18 \%$ & $31 \%$ & $0 \%$ & $0 \%$ & $0 \%$ & $0 \%$ \\
\hline Runaround loop savings (kWh) & 0.0 & 0.0 & 0.0 & 0.0 & 36.3 & 0.9 & 21.6 & 44.3 & 0.0 & 0.0 & 0.0 & 0.0 \\
\hline Setback savings (kWh) & 0.0 & 0.1 & 6.8 & 0.0 & 79.2 & 74.9 & 78.2 & 151.5 & 0.0 & 0.0 & 0.0 & 0.0 \\
\hline Setback preferred period (\%) & $68 \%$ & $54 \%$ & $60 \%$ & $69 \%$ & $60 \%$ & $80 \%$ & $100 \%$ & $99 \%$ & $100 \%$ & $86 \%$ & $85 \%$ & $50 \%$ \\
\hline \multicolumn{13}{|l|}{ Latent energy } \\
\hline $\begin{array}{r}\text { Uncontrolled dehumidification } \\
\text { period (\%) }\end{array}$ & $0 \%$ & $0 \%$ & $0 \%$ & $0 \%$ & $0 \%$ & $23 \%$ & $0 \%$ & $30 \%$ & $0 \%$ & $0 \%$ & $0 \%$ & $0 \%$ \\
\hline Humidifier operating period (\%) & $100 \%$ & $28 \%$ & $100 \%$ & $100 \%$ & $54 \%$ & $95 \%$ & $40 \%$ & $58 \%$ & $100 \%$ & $100 \%$ & $100 \%$ & $55 \%$ \\
\hline Humidification demand (kWh) & 246.0 & 34.0 & 245.4 & 341.9 & 131.9 & 342.9 & 86.1 & 140.6 & 246.7 & 438.2 & 246.0 & 371.0 \\
\hline $\begin{array}{r}\text { Humidification Setback savings } \\
\text { (kWh) }\end{array}$ & 123.0 & 17.1 & 122.7 & 171.1 & 66.0 & 171.7 & 43.1 & 70.4 & 123.4 & 218.7 & 123.0 & 201.9 \\
\hline $\begin{array}{r}\text { Demand due to uncontrolled } \\
\text { dehumidification (kWh) }\end{array}$ & 0.0 & 0.0 & 0.0 & 0.0 & 0.0 & 14.6 & 0.0 & 31.4 & 0.0 & 0.0 & 0.0 & 0.0 \\
\hline $\begin{array}{r}\text { Dehumidification Setback } \\
\text { savings (kWh) }\end{array}$ & 0.0 & 0.0 & 0.0 & 0.0 & 0.0 & 7.3 & 0.0 & 15.7 & 0.0 & 0.0 & 0.0 & 0.0 \\
\hline \multicolumn{13}{|l|}{ Electric energy } \\
\hline Setback savings (kWh) & 18.5 & 18.6 & 17.9 & 18.4 & 17.7 & 16.9 & 14.8 & 14.9 & 18.5 & 18.5 & 18.5 & 18.6 \\
\hline
\end{tabular}

Predicted setback savings for sensible heating slightly over real values also occurred during January (test 7), but estimated heating demand was higher than actual one, too. Having a closer look to registered data, this was because, during this test, temperature was supplied at the setpoint lower limit. This yielded lower heating needs than the predicted values, which considered the average supply temperature within the setpoint range of the AHU.

There would be no uncontrolled dehumidification for the TMY data. In the real tests, it only has an occasional occurrence. Given the negligible dehumidification, next section disregards the energy needs related. 
Electric savings achievable were easily predictable because airflows maintained at approximate constant values. It barely only affected the runaround operating periods expected, when the water pump power was saved if setback was applied instead.

\section{Applicability of setback. Discussion.}

Once studied the thermal and electric energy savings achievable and validated the appropriate maintenance of indoor safety through the operating room overpressure, this section gives an overview of the savings achievable yearly. It also approaches the effect of these savings on the energy supply to the $\mathrm{HCU}$, discussing the applicability of the strategy proposed, as well as the economic and environmental impact.

\subsection{Periods of applicability}

The applicability of the setback strategy corresponds to the non-occupation periods of the operating rooms. Currently, usual timetables of the operating rooms at the HCU are between 4.5 to 7.5 hours per working day (Monday to Friday), beyond use for urgent cases. This work approaches the first three of the possible scenarios for setback implementation:

A) Only during weekend (from Friday at 18:00 to Monday at 6:00).

B) Case A plus working days (Monday to Friday) from 18:00 to 6:00.

C) Case A plus working days (Monday to Friday) from 17:00 to 9:00.

D) Every time that the operating room is left unoccupied, with a 20 minutes delay.

To study the feasibility of these options, non-occupation periods expected are compared to the actual total periods of inactivity for the two target operating rooms available for 2018. The latter are shown in Figure 7.

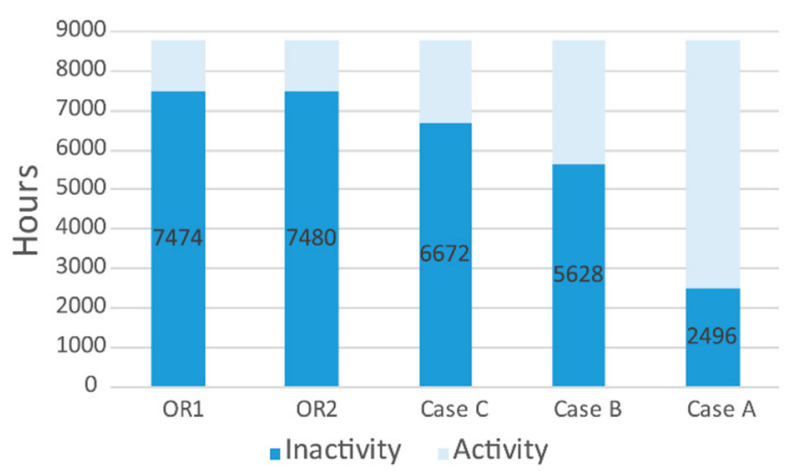

Figure 7. Total periods of inactivity of OR 1 and OR2 and expected cases during 2018.

Scenario B would correspond to unoccupancy periods considered in the literature (Porowski, 2019). Regarding the fact that both operating rooms were not in use for $85 \%$ of the time during 2018 , even scenario C, expecting inactivity for $76 \%$ of the time, seems feasible. Scenario (d) will not be considered in this study because it is not possible to estimate more precise nonoccupation periods. 
Next, Figure 8 shows the predicted preferable periods for operation of the setback strategy faced to the coil heat recovery (runaround loop). These periods are shown monthly for the three scenarios A, B and C.

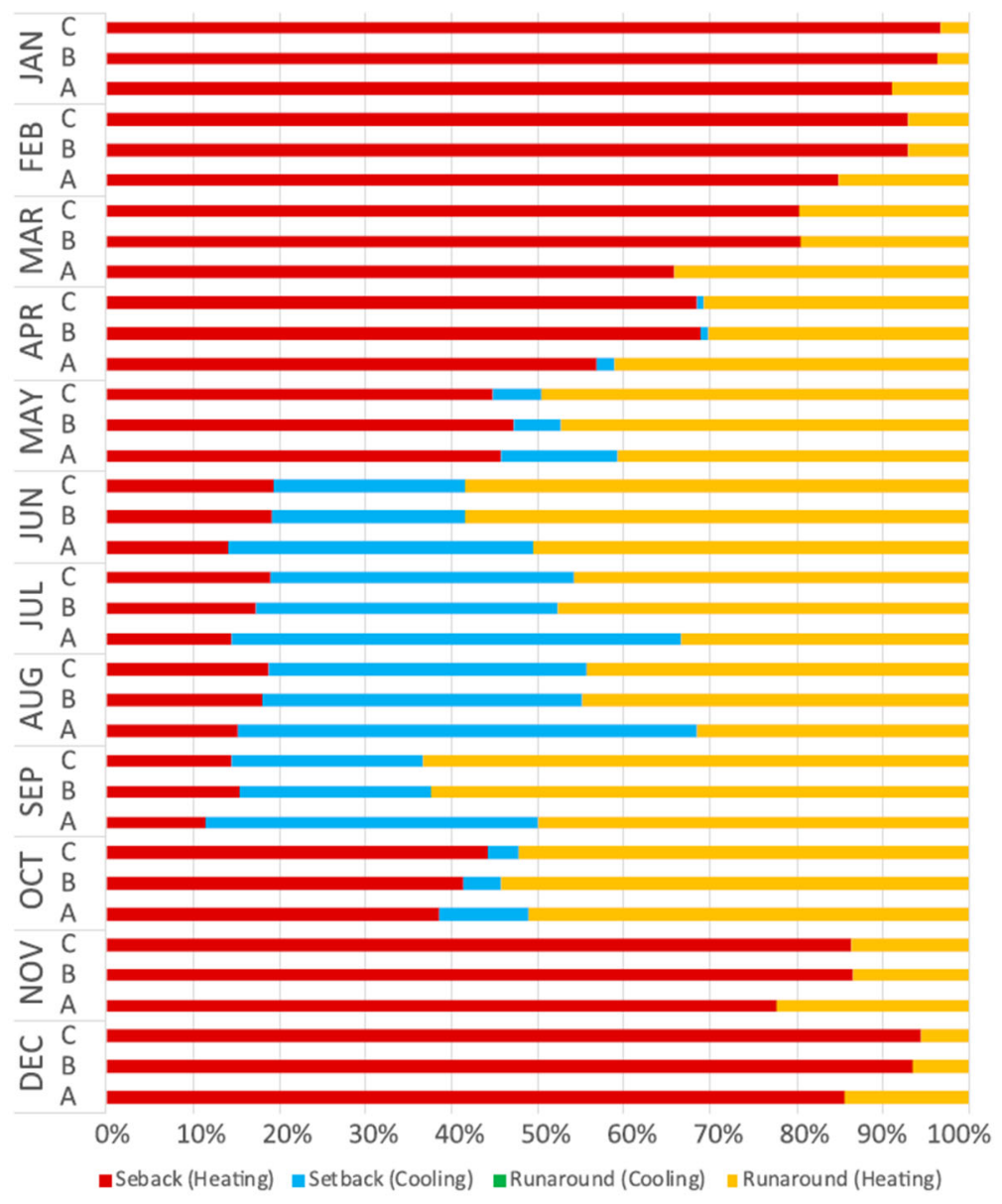

Figure 8. Monthly periods for preferred setback or heat recovery.

Figure 8 illustrates how setback is always preferable under cooling needs, as there are no periods when operation of the runaround loop would yield larger savings than setback (green bars). Taking a closer look to the periods when the runaround loop can operate (temperature differences larger than $5^{\circ} \mathrm{C}$ between outdoors and indoors) during cooling needs, these are limited and always longer for case A. Indeed, the longest periods correspond to August, when the runaround operate in cooling mode during $44 \%, 20 \%$ and $18 \%$ of the periods corresponding to cases $A, B$ and $C$, respectively. This is because scenarios B and C considered stretched nonoccupation periods of the operating rooms, mostly during night time, when outdoor temperature rarely exceed $5^{\circ} \mathrm{C}$ that of indoors. In the same line, cooling period is always larger in case $\mathrm{A}$.

If there is heating demand, setback is preferable instead of heat recovery during winter rather than in summer; hence, under larger temperature differences between indoors and outdoors.

Periods for setback preference would vary for different efficiencies of the runaround loop. Maximum efficiencies expected for this sort of heat recovery equipment are 65\% (ASHRAE, 2020), though for same supply and return airflows. At this upper limit, setback preference 
periods during Summer would remain similar, but would make the operation of the runaround more favourable than setback ventilation during Winter.

\subsection{Yearly supplied energy, economic savings and reduction in $\mathrm{CO}_{2}$ emissions.}

This section estimates energy savings as well as economic and $\mathrm{CO}_{2}$ emissions savings for scenarios A, B and C for the TMY of Valladolid.

The lower demand in fans and pumps directly introduce electric energy savings. Because vapour injection humidifiers and conventional refrigeration machines, respectively supply latent and cooling final energy needs, related supply energy is also electrical.

For the humidifier, the amount of water vapor $\left(m_{w}\right)$ injected will be:

$$
m_{w}=\frac{Q_{L}}{c_{L}}
$$

Where $Q_{L}$ is the latent energy and $c_{L}$ is the latent heat of water $(\mathrm{kJ} / \mathrm{kg})$.

Then, the electric energy required for the humidifier to provide this vapor will be:

$$
W_{\text {humidifier }}=m_{w} \cdot\left[c_{p w} \cdot\left(T_{\text {boiling }}-T_{\text {tap }}\right)+c_{L w}\right]
$$

Where tap water temperature $T_{\text {tap }}$ is the average value in Valladolid for each month (AENOR, $2005 \mathrm{a}$ ), being the boiling point $T_{\text {boiling }}=97.7^{\circ} \mathrm{C}$. In this equation, $c_{p w}$ refers to the specific heat $\left(\mathrm{kJ} /\left(\mathrm{kg}^{\circ} \mathrm{C}\right)\right)$ of water. Boiling latent heat at that temperature is $c_{L}=2672.5 \mathrm{~kJ} / \mathrm{kg}$.

For the chiller, the related electric energy savings result from the seasonal Energy Efficiency

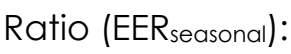

$$
W_{\text {chiller }}=\frac{Q_{\text {s cooling }}}{E E R_{\text {seasonal }}}
$$

Being $Q_{s \text { cooling }}$ the sensible energy demanded in the cooling coil (kWht). TheEERseasonal for the chillers installed in the $\mathrm{HCU}$ is 3.5 .

Concerning heating demand, it is important to note that the HCU is connected to the district heating of the University of Valladolid since $16^{\text {th }}$ January 2019. Although gas boilers had supplied heating demand until that date, the study disregards this short period for comparison.

Economic savings consider the available figures for 2019. Because energy consumption at a hospital is stable throughout the year, economic costs are estimated from an average cost of the kWh consumed. The HCU consumed 14,391 MWhe (MWhe accounting for electric energy) and spent above 1,761 thousands of euros $(k €)$ for this electric energy demand, while since $16^{\text {th }}$ January thermal energy consumed exceeded 10,660 MWh and costed $548 \mathrm{k} €$.

The reduction in $\mathrm{CO}_{2}$ emissions derives from the Spanish coefficients relating emissions to energy sources consumption, being $0.331 \mathrm{~kg} \mathrm{CO} / \mathrm{kWh}$ for electricity use and $0.018 \mathrm{~kg} \mathrm{CO} / \mathrm{kWh}$ for biomass (IDAE, 2016). Table 6 gathers the yearly economic savings and reduction in the $\mathrm{CO}_{2}$ emissions. Winter corresponds to months from November to April; Midseason comprises May, September and October, while Summer includes June to August. Results evidence that 
considerable savings are achievable in ORs with low use rate, though these are lower than the achieved ones for cleanrooms in the literature (Loomans et al., 2019). Savings in electric energy supplied for one operating room correspond to $53 \%$ of its demand, while Tschudi et al. (Tschudi et al., 2005) obtained $75 \%$ electric savings in cleanrooms. Present study provides more conservative results, because it contrasts setback ventilation savings to the achievable ones through an existing heat recovery system.

Table 6. Thermal and electric energy, economic and $\mathrm{CO}_{2}$ savings through setback.

\begin{tabular}{|c|c|c|c|c|c|c|c|c|c|}
\hline \multirow{2}{*}{$\begin{array}{c}\text { Season } \\
\text { Scenario }\end{array}$} & \multicolumn{3}{|c|}{ WINTER } & \multicolumn{3}{|c|}{ MIDSEASON } & \multicolumn{3}{|c|}{ SUMMER } \\
\hline & A & B & C & A & B & C & A & B & C \\
\hline \multicolumn{10}{|l|}{ Final energy savings (thermal) } \\
\hline Sensible heating (kWh/OR) & 547 & 1659 & 2034 & -48 & -131 & -162 & -71 & -224 & -254 \\
\hline Sensible cooling (kWh/OR) & 2 & 2 & 2 & 188 & 201 & 230 & 473 & 628 & 762 \\
\hline $\begin{array}{r}\text { Latent (humidification) } \\
\text { (kWh/OR) }\end{array}$ & 2559 & 5733 & 6791 & 947 & 2016 & 2467 & 752 & 1158 & 1505 \\
\hline \multicolumn{10}{|l|}{ Final energy savings (electric) } \\
\hline Fans and pumps (kWh/OR) & 385 & 862 & 1021 & 185 & 433 & 515 & 200 & 440 & 520 \\
\hline \multicolumn{10}{|l|}{ Supply energy savings } \\
\hline $\begin{array}{r}\text { Electric energy savings } \\
\text { (kWh/OR) }\end{array}$ & 3302 & 7398 & 8764 & 1311 & 2774 & 3375 & 1183 & 1925 & 2434 \\
\hline $\begin{array}{r}\text { Total electric energy savings } \\
\text { (kWh) }\end{array}$ & 59443 & 133169 & 157745 & 23606 & 49925 & 60755 & 21293 & 34650 & 43806 \\
\hline Total heating savings (kWh) & 9843 & 29867 & 36618 & -866 & -2362 & -2911 & -1278 & -4035 & -4563 \\
\hline \multicolumn{10}{|l|}{ Economic savings } \\
\hline Electricity ( $€ / O R)$ & 404 & 906 & 1073 & 161 & 339 & 413 & 145 & 236 & 298 \\
\hline Biomass (€/OR) & 28 & 85 & 104 & -2 & -7 & -8 & -4 & -12 & -13 \\
\hline Total economic savings $(€)$ & 7781 & 17834 & 21189 & 2845 & 5990 & 7287 & 2541 & 4034 & 5127 \\
\hline \multicolumn{10}{|l|}{$\mathrm{CO}_{2}$ emissions saved } \\
\hline Emissions per OR (kg/OR) & 1270 & 538 & 659 & -16 & -43 & -52 & -23 & -73 & -82 \\
\hline Total $(\mathrm{kg})$ & 22865 & 9677 & 11864 & -281 & -765 & -943 & -414 & -1308 & -1479 \\
\hline
\end{tabular}

Total savings consider the 18 ORs available in the HCU. This extrapolation is valid because all operating rooms have similar use, dimensions and there are no external walls, hence similar ventilation demand and thermal loads. Besides, all AHUs supply same air volume flows, while existing research demonstrated that energy consumption was proportional to the airflow rates (Alsved et al., 2018).

Total electric and heating energy savings given in Table 6 are for the whole surgical area with 18 operating rooms. The yearly sum of these results obtained for case C, would yield above 29 $\mathrm{MWh}$ theating and $262 \mathrm{MWh}$ e electric energy savings. The former corresponds to less than $0.3 \%$ of the actual thermal energy consumed in 2019. The latter would yield economic savings of up to $32 \mathrm{k} € /$ year. The expected electric savings correspond to $2 \%$ of the actual electric energy costs during 2019.Electric savings for the 18 operating rooms in case C during Summer reach 43.8 $\mathrm{MWh}_{\mathrm{e}}$. Near $70 \%$ savings through setback derive from minimising the humidification needs due to lower airflow rates in the dry outdoor conditions of the target climate. The decrease in the fans and pumps needs account for $21 \%$ of these savings. Consequently, obtained data 
shows that $10 \%$ difference in the seasonal EER of the chiller would yield only about $1 \%$ change for case $C$.

Real operating conditions would vary from the TMY data; however, for TMY provides less harsh climate data than the actual conditions and given the results derived from table 5, final savings may be better than the expected values if the setback strategy proposed is applied.

It must be remembered that results may differ considerably for other climates different from the temperate with dry, warm summers (Csb) of Valladolid, Spain. Because main savings yielded by setback were due to the decrease in the humidification needs and that no dehumidification occurred along the year, this will be most remarkable for humid climates. Nevertheless, the methodology proposed for the data estimation and analysis can be directly applied for any climate, as it considers all possible humidification and dehumidification cases, provided that no controlled dehumidification is required.

A final comment is needed after COVID-19 pandemic, which has demonstrated that unexpected requirements may come up. Energy saving strategies would be inane in such contexts. Setback ventilation could not be applied in these extraordinary situations, when operating rooms may operate under unusual negative air pressure conditions or be occupied for almost the whole day; however, normal operation of the operating room ventilation system can be restored at any time.

\section{Conclusions}

Periods of activity of Operating Rooms are very short, yet they need to be continuously conditioned to be prepared for possible occupation and avoid contamination through infiltrations from immediate spaces. Setback ventilation is among the possible strategies to improve energy efficiency related to operating rooms HVAC systems. This work applies setback in a case study - two operating rooms of the University Clinical Hospital (HCU) in Valladolid, Spain. The study demonstrates that its application would not threaten safety requirements and compares its efficiency to that of the existing coil heat recovery (runaround) loop, as simultaneous operation of both strategies is not possible. Main findings are:

- Setback ventilation does not hinder positive air pressure requirements. Overpressure indoors maintains at $15 \mathrm{~Pa}$, much above currently required values and those accepted in coming standards.

- Measured efficiency of the runaround loop coil heat exchanger is approximately $40 \%$, with a slight dependence on the temperature difference between airflows.

- Comparison to real data demonstrates that operation of the Air Handling Unit (AHU) of the operating rooms can be fairly estimated considering the setpoint parameters.

- During non-occupation periods throughout the whole year, overall savings achievable through setback are larger than those obtained by the heat recovery system.

- For the present case study under cooling needs, setback is always preferable to the runaround loop operation. 
- Supplied electric energy savings estimated reach $2 \%$ of the total hospital consumption during the year before.

- Real savings achievable would be larger than predicted, for the latter base on the milder TMY data.

Future research could focus on the identification of the optimal setpoint for operation of the coil heat exchanger (runaround) loop, considering both thermal savings and electric energy needs.

Building designers and engineers can take these results as reference to justify compliance with safety requirements when implementing ventilation strategies in cleanrooms, as well as in other spaces with positive air pressure needs.

Results on the energy savings introduced by setback ventilation in contrast to a runaround loop coil heat exchanger are for the Csb climate of Valladolid, Spain. The proposed estimation procedure can be directly applied to other climates where no controlled dehumidification is required in Summer. Future research can adapt the study to hot and humid climates.

\section{Acknowledgements}

Authors would like to acknowledge the managers and maintenance staff of the University Clinical Hospital of Valladolid for their permission and assistance when developing the study.

\section{Disclosure statement}

No potential conflict of interest was reported by the authors.

\section{Funding}

This work was supported by the Ente Regional de la Energía of the Regional Government of Castile and Leon [grant number EREN_2019_L2_UVA].

\section{References}

AENOR. (2005a). 31. Spanish standard. UNE 94002:2005 Instalaciones solares térmicas para producción de agua caliente sanitaria. Cálculo de la demanda de energía térmica.

AENOR. (2005b). Spanish standard: UNE 100713 - Instalaciones de acondicionamiento de aire en hospitales. AENOR.

AENOR. (2012). Spanish standard. UNE 171340:2012 Validación y cualificación de salas de ambiente controlado en hospitales.

Alsved, M., Civilis, A., Ekolind, P., Tammelin, A., Andersson, A. E., Jakobsson, J., ... Löndahl, J. (2018). Temperature-controlled airflow ventilation in operating rooms compared with laminar airflow and turbulent mixed airflow. Journal of Hospital Infection, 98(2), 181-190. https://doi.org/10.1016/j.jhin.2017.10.013

ASHRAE. (2017). Chapter 1. Psychrometrics. In ASHRAE Handbook-Fundamentals.

ASHRAE. (2019). Chapter 9. Healthcare Facilities. In ASHRAE Handbook. HVAC Applications. 
ASHRAE. (2020). Chapter 26. Air-to-air energy recovery equipment. In ASHRAE HandbookSystems and Equipment.

Berlanga, F. A., Olmedo, I., de Adana, M. R., Villafruela, J. M., José, J. F. S., \& Castro, F. (2018). Experimental assessment of different mixing air ventilation systems on ventilation performance and exposure to exhaled contaminants in hospital rooms. Energy and Buildings, 177, 207-219. https://doi.org/10.1016/j.enbuild.2018.07.053

CADDET. (1997). Saving energy with Energy Efficiency in Hospitals.

Castro Ruiz, F., San José Alonso, J. F., Villafruela Espina, J. M., \& Guijarro Rubio, Á. (2011). Manual de diseño de la climatización y ventilación de quirófanos y habitaciones en centros hospitalarios en Castilla y León.

CEN. (1997). EN 308:1997 Heat exchangers - Test procedures for establishing performance of air to air and flue gases heat recovery devices. European Committee for Standardization (CEN).

CEN. (2017). EN 16798-3 Energy performance of buildings - Ventilation for buildings - Part 3: For non-residential buildings - Performance requirements for ventilation and room-conditioning systems (Modules M5-1, M5-4).

D'Orazio, A., Galea, M. P., Maddaloni, F., \& Poggi, L. (2016). Experimental Evaluation of the Pollutant Distribution in an Operating Theater of a University Hospital of Rome. In ASHRAE and AIVC IAQ 2016.

Dyer, D. F., \& O'Mary, C. (2011). Case study: Energy audit and implementation at the Russell Medical Center. WIT Transactions on Ecology and the Environment, 143, 195-201. https://doi.org/10.2495/ESUS1 10171

EPTA. (2007). LIFE04 ENV/GR/0001 14 Guidelines for energy efficiency in hospitals. Retrieved from http://ec.europa.eu/environment/life/project/Projects/files/book/LIFE04ENVGR1 14-EE.pdf

FENERCOM. (2012). Guía de Ahorro y Eficiencia Energética en Hospitales. Retrieved from https://www.fenercom.com/pdf/publicaciones/Guia-de-Ahorro-y-Eficiencia-Energetica-enHospitales-fenercom-2010.pdf

García-Sanz-Calcedo, J., Al-Kassir, A., \& Yusaf, T. (2018). Economic and Environmental Impact of Energy Saving in Healthcare Buildings. Applied Sciences, 8(3), 440. https://doi.org/10.3390/app8030440

González González, A., García-Sanz-Calcedo, J., \& Rodríguez Salgado, D. (2018). Evaluation of Energy Consumption in German Hospitals: Benchmarking in the Public Sector. Energies, 11 (9), 2279. https://doi.org/10.3390/en1 1092279

Gormley, T., Markel, T. A., Jones, H., Greeley, D., Ostojic, J., Clarke, J. H., ... Wagner, J. (2017). Cost-benefit analysis of different air change rates in an operating room environment. American Journal of Infection Control, 45(12), 1318-1323. https://doi.org/10.1016/j.ajic.2017.07.024

IDAE. (2001). La guía técnica de eficiencia energética en iluminación, hospitales y centros de atención primaria. 
IDAE. (2016). Factores de emisión de CO2 y coeficientes de paso a energía primaria de diferentes fuentes de energía final consumidas en el sector de edificios en España. Retrieved from

https://energia.gob.es/desarrollo/EficienciaEnergetica/RITE/Reconocidos/Reconocidos/Otros documentos/Factores_emision_CO2.pdf

ISO 14644-1. (2015). Cleanrooms and associated controlled environments. Part 1: Classification of air cleanliness by particle concentration.

Joppolo, C. M., \& Romano, F. (2017). HVAC System Design in Healthcare Facilities and Control of Aerosol Contaminants: Issues, Tools, and Experiments. In S. Capolongo, M. Gola, \& G. Settimo (Eds.), Indoor Air Quality (IAQ) in Healthcare Facilities (pp. 83-94). Springer International Publishing. https://doi.org/10.1007/978-3-319-49160-8

Kassai, M., Poleczky, L., Al-Hyari, L., Kajtar, L., \& Nyers, J. (2018). Investigation of the energy recovery potentials in ventilation systems in different climates. Facta Universitatis, Series: Mechanical Engineering, 16(2), 203-217. https://doi.org/10.22190/FUME180403017K

Loomans, M. G. L. C., Molenaar, P. C. A., Kort, H. S. M., \& Joosten, P. H. J. (2019). Energy demand reduction in pharmaceutical cleanrooms through optimization of ventilation. Energy and Buildings, 202. https://doi.org/10.1016/j.enbuild.2019.109346

Mathews, E. H., Botha, C. P., Arndt, D. C., \& Malan, A. (2001). HVAC control strategies to enhance comfort and minimise energy usage. Energy and Buildings, 33(8), 853-863. https://doi.org/10.1016/S0378-7788(01)00075-5

NationalGrid. (2002). Managing Energy Costs in Hospitals. Retrieved from http://www9.nationalgridus.com/non_html/shared_energyeff_hospitals.pdf

Pastor Pérez, P. (2012). Documentos Técnicos de Instalaciones en la Edificación DTIE 1.06: Instalación de climatización en hospitales. (ATECYR, Ed.). Madrid: ATECYR.

Pérez-Lombard, L., Ortiz, J., Coronel, J. F., \& Maestre, I. R. (2011). A review of HVAC systems requirements in building energy regulations. Energy and Buildings, 43(2-3), 255-268. https://doi.org/10.1016/J.ENBUILD.2010.10.025

Porowski, M. (2019). Energy optimization of HVAC system from a holistic perspective: Operating theater application. Energy Conversion and Management, 182, 461-496. https://doi.org/10.1016/j.enconman.2018.12.003

Ramos, J. J. (2018). Grandes demandas de energía: Hospitales. Bioenergy International, (2), 31. Retrieved from https://bioenergyinternational.es/1621-2/

Sala, M., Alcamo, G., \& Ceccherini Nelli, L. (2017). Energy-Saving solutions for five Hospitals in Europe. In Mediterranean Green Buildings and Renewable Energy: Selected Papers from the World Renewable Energy Network's Med Green Forum. Springer International Publishing. https://doi.org/10.1007/978-3-319-30746-6

Sánchez-Barroso Moreno, G., García-Sanz Calcedo, J., González, A. G., \& Salgado, D. R. (2019). Sustainable solutions for thermal energy saving in hospital operating theatres. E3S Web of Conferences, 85, 01002. https://doi.org/10.1051/e3sconf/20198501002 
Short, C. A., \& Al-Maiyah, S. (2009). Design strategy for low-energy ventilation and cooling of hospitals. Building Research and Information, 37(3), 264-292. https://doi.org/10.1080/09613210902885156

Tejero-González, A., Andrés-Chicote, M., García-lbáñez, P., Velasco-Gómez, E., \& ReyMartínez, F. J. (2016). Assessing the applicability of passive cooling and heating techniques through climate factors: An overview. Renewable and Sustainable Energy Reviews. https://doi.org/10.1016/j.rser.2016.06.077

The European Parliament and the Council of the European Union. (2018). Directive (EU) 2018/844 of the European Parliament and of the Council of 30 May 2018 amending Directive $2010 / 31$ /EU on the energy performance of buildings and Directive 2012/27/EU on energy efficiency.

Tschudi, W., Faulkner, D., \& Hebert, A. (2005). Energy efficiency strategies for cleanrooms without compromising environmental conditions. ASHRAE Transactions, 111 PART 2, 637-645.

USAID/GOI. (2009). Energy efficiency in hospitals Best practice Guide. Retrieved from https://www.beeindia.gov.in/sites/default/files/HospitalEnergyEfficiencyBestPracticesGuide.p df

Wang, F. J., Chang, T. B., Lai, C. M., \& Liu, Z. Y. (2012). Performance improvement of airflow distribution and contamination control for an unoccupied operating room. Retrieved from http://www.ibpsa.org/proceedings/asim2012/0130.pdf

Woods, J. E., Reynolds, G. L., Montag, G. M., Braymen, D. T., \& Rasmussen, R. W. (1986). Ventilation Requirements in Hospital Operating Rooms - Part li: Energy and Economic Implications. ASHRAE Transactions, 92(pt 2A), 427-449.

Yau, Y. H., \& Ng, W. K. (2011). A comparison study on energy savings and fungus growth control using heat recovery devices in a modern tropical operating theatre. Energy Conversion and Management, 52(4), 1850-1860. https://doi.org/10.1016/J.ENCONMAN.2010.12.005

Zhuang, C., Wang, S., \& Shan, K. (2019). Adaptive full-range decoupled ventilation strategy and air-conditioning systems for cleanrooms and buildings requiring strict humidity control and their performance evaluation. Energy, 168, 883-896. https://doi.org/10.1016/j.energy.2018.11.147 